\title{
An Inventory Model of Production with Level Dependent Demand Allowing Few Defective Items
}

\author{
Md. Jamil Uddin'1, Shirajul Islam Ukil ${ }^{2}$, Aminur Rahman Khan'1, Md. Sharif Uddin'1 \\ ${ }^{1}$ Department of Mathematics, Jahangirnagar University, Savar, Dhaka, Bangladesh \\ ${ }^{2}$ Department of Mathematics, Bangladesh Military Academy, Bhatiary, Chattogram, Bangladesh \\ Email: shirajukil@yahoo.com
}

How to cite this paper: Uddin, Md.J., Ukil, S.I., Khan, A.R. and Uddin, Md.S. (2021) An Inventory Model of Production with Level Dependent Demand Allowing Few Defective Items. American Journal of Operations Research, 11, 1-14.

https://doi.org/10.4236/ajor.2021.111001

Received: November 3, 2020

Accepted: January 10, 2021

Published: January 13, 2021

Copyright $\odot 2021$ by author(s) and Scientific Research Publishing Inc. This work is licensed under the Creative Commons Attribution International License (CC BY 4.0).

http://creativecommons.org/licenses/by/4.0/

\begin{abstract}
This paper considers a model regarding the products with finite life which allows defective items in reproduction and causes a small amount of decay. The market demand is assumed to be level dependent linear type. The model has also considered the constant production rate which stops after a desired level of inventories and that is the highest level of it. Due to the market demand, defective item and product's decay, the inventory reduces to the zero level where again the production cycle starts. With a numerical search procedure, the proof of the proposed model has been shown. The objective of the proposed model is to find out the total optimum inventory cost, optimum ordering cost and optimum ordering cycle.
\end{abstract}

\section{Keywords}

Production Inventory, Linear Demand, Defective Item and Constant Production Rate

\section{Introduction}

Inventory management in any business is nowadays considered as a very important issue in the market. Thereby how it will be managed and how much is to be produced and supplied based on demand gets an important role here in this twentieth century. Thereby inventory problems had been started to study much more than before. Inventory is a stock of materials either raw or finished product. Analysing the inventory problem helps to minimize the inventory cost and time. There are two kinds of materials in the market, one has damage, wastage, deterioration or decay and the other one does not have. Items like radioactive 
substances, food grains, fashionable items, pharmaceuticals etc. are the items of finite life and the items like electronic goods, steels, woods etc. are the items of long life. The deterioration affects the inventory and inventory cost increases. To make the inventory cost at optimum level, a suitable inventory model is required to be formulated. In minimizing inventory cost and time this paper proposes an inventory model with linear demand, production with few defective items in the cycle, small amount of decay and constant production rate. The production starts with zero inventories in the model discussed in this paper. After a certain period, it gets the highest inventory and production stops. This paper has also considered constant production rate along with the deterioration. Finally, proving the convex properties and using a numerical example, the paper justified the correctness of the model. The objective of the proposed model is to get the optimum inventory cost, time and ordering cycle. The paper concludes with literature review, assumptions and notations, development of the model, numerical illustration and sensitivity analysis.

\section{Literature Review}

Since long the researchers had been trying to get the inventory models which can meet the needs in real life. They were solving many types of inventory problems. The problems are related with various types of demand in the market, types of production rate of the business organizations, finite life of the products, defective production items, whether backlogs or shortages and delay in payments are allowed etc. Most of the researchers had structured different types of inventory models mainly focusing demand pattern which may be linear, quadratic, trapezoidal, exponential, time dependent, level or stock dependent, price dependent etc. Considering all the parameters two types of models in this field are designed, one is deterministic model which deals with the constant demand and lead time; the other one is stochastic or probabilistic model which deals randomly with the variable demand and lead time. In the review of the literature, the inventory models with deterministic demand have been given importance. Determining Economic Order Quantity (EOQ) is one of the most important factors to formulate the inventory models. The ultimate objective of formulating the model is to minimize the inventory cost by finding the EOQ. So far it is known that Harris [1] was the first researcher to study the inventory model and he opened a new dimension in the field of the inventory control management since he presented the famous EOQ formula. For the first time, Whitin [2] constructed the inventory model which was suitable for fashionable goods and he allowed its little decay in the inventory. Ghare and Schrader [3] first pointed out the effect of decay in inventory analysis and discovered the economic order quantity (EOQ) model. The nature of the consumption of the deteriorating items was proved by them. Hou [4] derives an inventory model for deteriorating items with stock dependent consumption rate and shortages under inflation. On the basis of stock dependent selling rate, Chund and Wee [5] developed an integrated two stages production inventory deteriorating model for the buyer and 
the supplier considering imperfect items and just in time (JIT) multiple deliveries. Heng et al. [6] placed an order level lot size inventory model for deteriorating items and finite replenishment rate. Skouri and Papachristos [7] discussed a continuous review inventory model considering the five costs as deterioration, holding, shortage, opportunity cost due to the lost sales and the replenishment cost due to the linearly dependency on the lot size. Applying inventory replenishment policy Mingbao and Wang [8] constructed the inventory model for deteriorating items with trapezoidal type demand rate, where the demand rate is a piecewise linearly functions. Sarker et al. [9] explained an inventory model where demand was a composite function consisting of a constant component and a variable component proportional to inventory level in a period and decay was exponential and inventory was positive, whereas Sana and Chaudhuri [10] explained the level dependent demand with finite decay. Shah and Jaiswal [11] and Dye [12] established an inventory model by considering demand as a function of selling price and three parameters of Weibull rate of deterioration. Hassan and Bozorgi [13] developed the location of distribution centers with inventory. Khieng et al. [6] presented a production model for the lot-size, order level inventory system with finite production rate and the effect of decay. Mishra et al. [14] explained an inventory model for deteriorating items with time dependent demand and time varying holding cost under partial backlogging. Ekramol [15] [16] considered various production rates where the demand is constant. Shiraj [17] discussed the effect of just in time manufacturing system on EOQ model. Sivazlian and Stenfel [18] determined the optimum value of time cycle by using the graphical solution of the equation to obtain the economic order quantity model. Pakkala and Achary [19] established a deterministic inventory model for deteriorating items with two warehouses, considering the replenishment rate was finite and demand was uniform, while shortage was allowed. Billington [20] explained how classic economic production quantity (EPQ) model is formulated without backorders or backlogs. Abad [21] discussed regarding optimal pricing and lot sizing under conditions of perish ability and partial backordering. Sing and Pattanak [22] [23] [24] developed the model for deterioration and time dependent quadratic demand under permissible delay in payment, whereas we have used the demand of linear trend but ignoring the payment aspect. Giri et al. [25] placed a model with time varying demand and costs. Amutha and Chandrasekaran [26] formulated the inventory model with deterioration items, quadratic demand and time dependent holding cost, but in our proposed model, we have emphasized on the production rate, linear type of demand and constant holding cost. Ouyang and Cheng [27] explained the inventory model for deteriorating items with exponential declining demand and partial backlogging. Dave and Patel [28] introduced an inventory model for deteriorating items with time proportional demand, but we have considered the demand which is level dependent. Teng et al. [29] developed the model with deteriorating items and shortages assuming that the demand function was positive and fluctuating with respect to time, but in the proposed model, the demand was considered as a li- 
near function and production starts, allowing few items defective in production cycle, which may be used in the next cycle again.

\section{Assumptions}

1) Production rate is constant and greater than the summation of defective items and demand rate at any time.

2) Demand is a linear function.

3) For unit inventory, amount of decay rate is very small and constant.

4) Production starts allowing that few amounts of items will be defective in the inventory which will be used in the production system in the next cycle.

5) Inventory level is highest at a specific level and after that, the inventory depletes quickly due to demand and deterioration.

6) Shortages are not allowed.

7) Lead time is zero.

\section{Notations}

$\lambda=$ Production rate

$d=$ Defective items in the process of production.

$a=$ Demand rate at any instant $\theta$, satisfying the condition $\lambda>d+a$.

$\mu=$ Very small amount of constant decay rate for unit inventory.

$I(\theta)=$ Inventory level at instant $\theta$.

$\mathrm{d} \theta=$ Vary small portion of instant $\theta$.

$A$ and $B=$ Arbitrary constants.

$I_{1}=$ Un-decayed inventory at $T=0$ to $t_{1}$.

$I_{2}=$ Un-decayed inventory at $T=t_{1}$ to $T_{1}$.

$D_{1}=$ Deteriorating inventory at $T=0$ to $t_{1}$.

$D_{2}=$ Deteriorating inventory at $T=t_{1}$ to $T_{1}$.

$I(\theta)=0, Q$ and $0=$ Inventory level at time $T=0, t_{1}$ and $T_{1}$ respectively. $Q$ is the highest inventory which also depicts the order quantity as well.

$K=$ Set up cost.

$h=$ Holding cost.

$T C=T C(Q)=$ Total inventory cost in terms of $Q$.

$t_{1}=$ Time when inventory gets maximum level.

$T_{1}=$ Total time cycle.

$Q_{1}^{*}=$ Optimum order quantity.

$t_{1}^{*}=$ Optimum time at maximum inventory.

$T_{1}^{*}=$ Optimum time cycle.

$T C^{*}=$ Total optimum inventory cost.

\section{Development of the Model}

It is learned that generally, on the basis on the demand pattern; the business institution confirms the design of the model. In reality, the demand may at times be dependent on the level or the stock on hand in the inventory. To meet this 
type of situation, this model is developed. Few productive items may be defective which will go to the reproduction cycle again than it goes to the fulfilment of the demand. The model is suitable for the products which have finite life and causes the products decay due to its limited life. At the beginning, while time $T=0$, the production $\lambda$ starts allowing few products $d$ as defective items and $Q$ as inventories and the production remains constant for entire production cycle (follow Figure 1).

The inventory increases at the rate of $\lambda-d-a-\mu I(\theta)$ during $T=0$ to $t_{1}$ where $d$ is the defective items produced in the production cycle, $a$ is the market demand and $\mu I(\theta)$ is the decay of $I(\theta)$ inventories at instant $\theta$ mentioning that, $\mu$ is the decay of unit inventory in the period. With the above conditions the following differential equation can be formulated:

$$
\begin{aligned}
& I(\theta+\mathrm{d} \theta)=I(\theta)+\{\lambda-d-a\} \mathrm{d} \theta-\mu I(\theta) \mathrm{d} \theta \\
& \text { or, } I(\theta+\mathrm{d} \theta)-I(\theta)=\{\lambda-d-a-\mu I(\theta)\} \mathrm{d} \theta \\
& \text { or, } \lim _{\mathrm{d} \theta \rightarrow 0} \frac{I(\theta+\mathrm{d} \theta)-I(\theta)}{\mathrm{d} \theta}=\lambda-d-a-\mu I(\theta) \\
& \text { or, } \frac{\mathrm{d}}{\mathrm{d} \theta} I(\theta)+\mu I(\theta)=\lambda-d-a
\end{aligned}
$$

The general solution of the differential equation is,

$$
I(\theta)=\frac{\lambda-d-a}{\mu}+A \mathrm{e}^{-\mu \theta}
$$

Applying the boundary condition at $\theta=0$, we get, $I(\theta)=0$.

By Solving these equations, we get, $A=-\frac{\lambda-d-a}{\mu}$.

Therefore, taking up to first degree of $\mu$ we get,

$$
\begin{aligned}
& I(\theta)=\frac{\lambda-d-a}{\mu}-\frac{\lambda-d-a}{\mu} \mathrm{e}^{-\mu \theta} \\
& =\frac{\lambda-d-a}{\mu}\left(1-\mathrm{e}^{-\mu \theta}\right) \\
& =\frac{\lambda-d-a}{\mu} \mu \theta \\
& \text { or, } I(\theta)=(\lambda-d-a) \theta
\end{aligned}
$$

From the other boundary condition, i.e. at $\theta=t_{1}, I(\theta)=Q$, taking up to first degree of $\mu$, we get the following equation:

$$
\begin{aligned}
Q & =\frac{\lambda-d-a}{\mu}-\frac{\lambda-d-a}{\mu} \mathrm{e}^{-\mu t_{1}} \\
& =\frac{\lambda-d-a}{\mu}\left(1-\mathrm{e}^{-\mu t_{1}}\right) \\
& =\frac{\lambda-d-a}{\mu} \mu t_{1}
\end{aligned}
$$$$
\text { or, } Q=(\lambda-d-a) t_{1}
$$ 


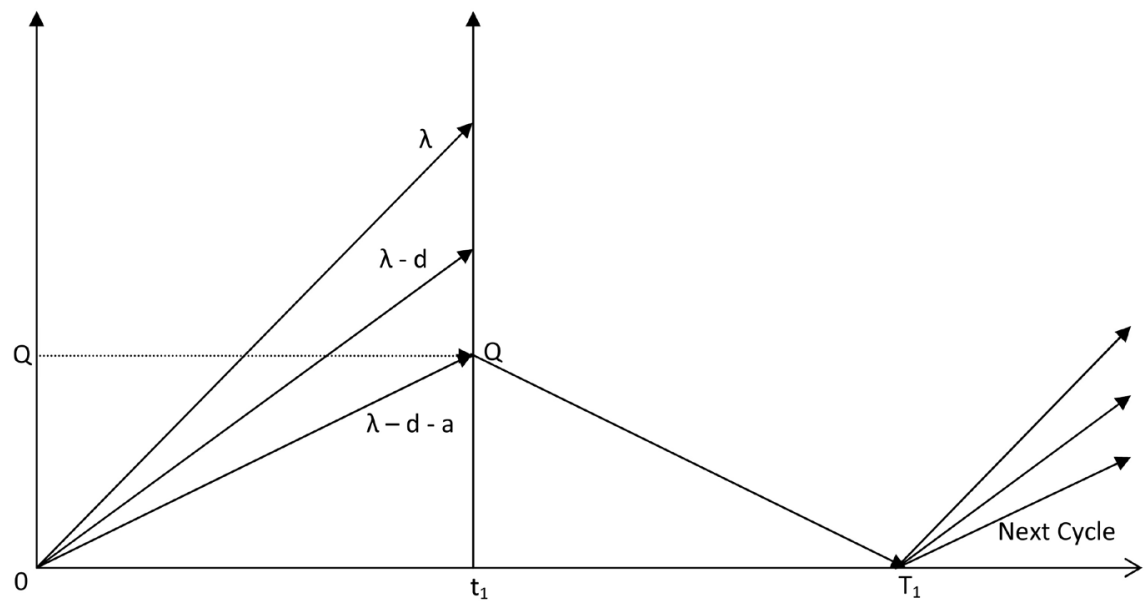

Figure 1. Production-demand cycle.

Using the Equation (3) and considering up to second degree of $\mu$ for our convenience, the total un-decayed inventory during $\theta=0$ to $t_{1}$ we get,

$$
\begin{aligned}
I_{1} & =\int_{0}^{t_{1}} I(\theta) \mathrm{d} \theta=\int_{0}^{t_{1}}[(\lambda-d-a) \theta] \mathrm{d} \theta \\
& =\left[(\lambda-d-a) \frac{\theta^{2}}{2}\right]_{0}^{t_{1}}=\frac{1}{2} t_{1}^{2}(\lambda-d-a) \\
& =\frac{1}{2} \frac{Q^{2}}{(\lambda-d-a)^{2}}(\lambda-d-a)=\frac{1}{2} \frac{Q^{2}}{\lambda-d-a}
\end{aligned}
$$

We calculate the deteriorating items during the period considering the decay of the items as below:

$$
\begin{aligned}
D_{1} & =\int_{0}^{t_{1}} \mu I(\theta) \mathrm{d} \theta=\mu \int_{0}^{t_{1}}[(\lambda-d-a) \theta] \mathrm{d} \theta \\
& =\mu\left[(\lambda-d-a) \frac{\theta^{2}}{2}\right]_{0}^{t_{1}}=\frac{1}{2} \mu t_{1}^{2}(\lambda-d-a) \\
& =\frac{1}{2} \mu \frac{Q^{2}}{(\lambda-d-a)^{2}}(\lambda-d-a)=\frac{1}{2} \frac{\mu Q^{2}}{\lambda-d-a}
\end{aligned}
$$

On the other hand, the inventory decreases at the rate of $a+\mu I(\theta)$ during $T=t_{1}$ to $T_{1}$ as there is no production after time $t_{1}$. In this step, the inventory depletes due to market demand and the deterioration of the items. Similar approach as used before can be applied to get another differential equation which is as below:

$$
\frac{\mathrm{d}}{\mathrm{d} \theta} I(\theta)+\mu I(\theta)=-a
$$

The general solution of the differential equation is defined below:

$$
I(\theta)=\frac{-a}{\mu}+B \mathrm{e}^{-\mu \theta}
$$

Applying the boundary condition at $\theta=T_{1}$, we get, $I(\theta)=0$. 
By solving we get, $B=\frac{a}{\mu} \mathrm{e}^{\mu T_{1}}$

Therefore,

$$
I(\theta)=\frac{a}{\mu}\left[\mathrm{e}^{\mu\left(T_{1}-\theta\right)}-1\right]
$$

Taking the first degree of $\mu$, we get the equation as below:

$$
I(\theta)=a\left(T_{1}-\theta\right)
$$

Substituting another boundary condition in Equation (10), i.e. at $\theta=t_{1}$, $I(\theta)=Q$, taking up to first order of $\mu$, we get the following equation:

$$
\begin{aligned}
Q & =a\left(T_{1}-t_{1}\right) \\
\text { or, } Q & =a\left(T_{1}-\frac{Q}{\lambda-d-a}\right) \\
\text { or, } a T_{1} & =\frac{Q(\lambda-d)}{\lambda-d-a} \\
\text { or, } T_{1} & =\frac{Q(\lambda-d)}{a(\lambda-d-a)}
\end{aligned}
$$

Now, using the Equation (10) and considering up to the first degree of $\mu$ we get the un-decayed inventory during $T=t_{1}$ to $T_{1}$ as:

$$
\begin{aligned}
I_{2} & =\int_{t_{1}}^{T_{1}} I(\theta) \mathrm{d} \theta=\int_{t_{1}}^{T_{1}}\left\{a\left(T_{1}-\theta\right)\right\} \mathrm{d} \theta=\int_{t_{1}}^{T_{1}}\left\{a\left(\frac{Q(\lambda-d)}{a(\lambda-d-a)}-\theta\right)\right\} \mathrm{d} \theta \\
& =a\left[T_{1} \theta-\frac{\theta^{2}}{2}\right]_{t_{1}}^{T_{1}}=a T_{1}\left(T_{1}-t_{1}\right)-\frac{a}{2}\left(T_{1}^{2}-t_{1}^{2}\right) \\
& =a\left(T_{1}-t_{1}\right)\left(\frac{1}{2} T_{1}-\frac{1}{2} t_{1}\right)=\frac{1}{2} a\left(T_{1}-t_{1}\right)^{2} \\
& =\frac{1}{2} a\left\{\frac{Q(\lambda-d)}{a(\lambda-d-a)}-\frac{Q}{\lambda-d-a}\right\}^{2} \quad[\text { putting the values from (3) and }(12)] \\
& =\frac{1}{2} \frac{Q^{2}}{a}
\end{aligned}
$$

Considering the decay of the items, we calculate the deteriorating items during the period as below:

$$
D_{2}=\int_{t_{1}}^{T_{1}} \mu I(\theta) \mathrm{d} \theta=\int_{t_{1}}^{T_{1}} \mu\left\{a\left(T_{1}-\theta\right)\right\} \mathrm{d} \theta=\frac{1}{2} \frac{\mu Q^{2}}{a}
$$

Total Cost Function: The cost function can be described in the following form,

$$
T C(Q)=\frac{K+h\left(I_{1}+I_{2}\right)+\delta\left(D_{1}+D_{2}\right)}{T_{1}}
$$

By substituting the values of Equation (5), Equation (6), Equations (12)-(14) in Equation (15), we get the value of total inventory cost as below, 


$$
\begin{aligned}
T C= & \frac{1}{T_{1}}\left[K+h \frac{Q^{2}}{2(\lambda-d-a)}+h \frac{Q^{2}}{2 a}+\delta \frac{\mu Q^{2}}{2(\lambda-d-a)}+\delta \frac{Q^{2}}{2 a}\right] \\
= & \frac{1}{T_{1}}\left[K+\frac{Q^{2}(h+\delta \mu)}{2(\lambda-d-a)}+\frac{Q^{2}(h+\delta \mu)}{2 a}\right] \\
= & \frac{a(\lambda-d-a)}{Q(\lambda-d)}\left[K+\frac{Q^{2}(h+\delta \mu)}{2(\lambda-d-a)}+\frac{Q^{2}(h+\delta \mu)}{2 a}\right] \\
= & \frac{K a(\lambda-d-a)}{Q(\lambda-d)}+\frac{a(\lambda-d-a)}{Q(\lambda-d)} \times \frac{Q^{2}(h+\delta \mu)}{2(\lambda-d-a)} \\
& +\frac{a(\lambda-d-a)}{Q(\lambda-d)} \times \frac{Q^{2}(h+\delta \mu)}{2 a} \\
= & \frac{K a(\lambda-d-a)}{Q(\lambda-d)}+(h+\delta \mu)\left[\frac{a Q}{2(\lambda-d)}+\frac{a(\lambda-d-a)}{2(\lambda-d)}\right] \\
= & \frac{K a(\lambda-d-a)}{Q(\lambda-d)}+\frac{Q(h+\delta \mu)}{2}
\end{aligned}
$$

The total inventory cost is depicted by the Equation (15). Now the objective is to minimize the total inventory cost and time. With a view to obtaining the order quantity $Q^{*}$ that minimizes the total inventory cost for the inventory system, we shall adopt the convex property. To obtain the optimum order quantity and verify the Equation (15) as convex in $Q$, we must satisfy the following well established convex properties,
1) $\frac{\mathrm{d}}{\mathrm{d} Q} T C=0$
2) $\frac{\mathrm{d}^{2}}{\mathrm{~d} Q^{2}} T C>0$

Now differentiating the Equation (15) with respect to $Q$ we get the following equation,

$$
\frac{\mathrm{d} T C}{\mathrm{~d} Q}=-\frac{K a(\lambda-d-a)}{Q^{2}(\lambda-d)}+\frac{h+\delta \mu}{2}
$$

The second derivative of the Equation (15) with respect to $Q$ is as below:

$$
\frac{\mathrm{d}^{2} T C}{\mathrm{~d} Q^{2}}=\frac{2 K a(\lambda-d-a)}{Q^{3}(\lambda-d)}+\frac{h+\delta \mu}{2}
$$

The Equation (18) is always positive as $K, Q, a, h, \delta, \mu,(\lambda-d-a),(\lambda-d)$ all are positive. Hence the second property exists, i.e. $\frac{\mathrm{d}^{2}}{\mathrm{~d} Q^{2}} T C>0$

Now to meet the first property, from Equation (17), we get,

$$
\frac{K a(\lambda-d-a)}{Q^{2}(\lambda-d)}=\frac{h+\delta \mu}{2}
$$

By solving this equation, we get the optimum order quantity $Q^{*}$ as below:

$$
Q^{*}=\sqrt{\frac{2 K a(\lambda-d-a)}{(h+\delta \mu)(\lambda-d)}}
$$


Finally, we conclude that total cost function (16) is convex in $Q$. Hence, there is an optimal solution in $Q$ for which the total inventory cost must be minimal. From the Equation (12), we get the total optimum time cycle $T_{1}^{*}$ as below:

$$
T_{1}^{*}=\sqrt{\frac{2 K(\lambda-d)}{a(h+\delta \mu)(\lambda-d-a)}}
$$

\section{Numerical Illustration}

To justify the model, we give an example that may illustrate how the numerical search procedure works. Suppose that the demand is a linear function in the inventory system and adopts the following parameters:

$$
K=100, \lambda=15, d=1, a=2, h=2, \delta=0.01 \text { and } \mu=0.02 \text {. }
$$

We now put all the values in Equation (4), Equation (15), Equation (20) and Equation (21) and we get the following results by using the scientific calculator:

$>$ Optimum order interval $Q^{*}=13.10$ units;

$>$ Optimum time $t_{1}^{*}=1.09$ units at maximum inventory level;

Optimum order quantity $T_{1}^{*}=7.64$ units;

Total optimum inventory cost $T C^{*}=26.19$ units.

Inventory cost gradually increases from the optimum level if the values of $Q$ gets either bigger or lesser than $Q^{*}$ arbitrarily. The comparison is shown in Table 1 and Figure 2. The table and figure justify the total optimum inventory cost.

\section{Sensitivity Analysis}

Now, how a little changes of parameters $k, \lambda, d, a, h, \delta$ and $\mu$ on the optimal

Table 1. Order Quantity $(Q)$ verses total cost $(T C)$.

\begin{tabular}{cccccccccc}
\hline Serial & $(1)$ & $(2)$ & $(3)$ & $(4)$ & $(5)$ & $(6)$ & $(7)$ & $(8)$ & $(9)$ \\
\hline Order Quantity $(Q)$ & 05.00 & 07.00 & 09.00 & 11.00 & 13.10 & 17.00 & 21.00 & 25.00 & 29.00 \\
Total Cost (TC) & 39.29 & 31.49 & 28.05 & 26.59 & 26.19 & 27.09 & 29.17 & 31.86 & 34.91 \\
Remarks & $\begin{array}{l}\text { At a particular inventory level total cost is minimum, before and after this } \\
\text { point total cost increases }\end{array}$ \\
\hline
\end{tabular}

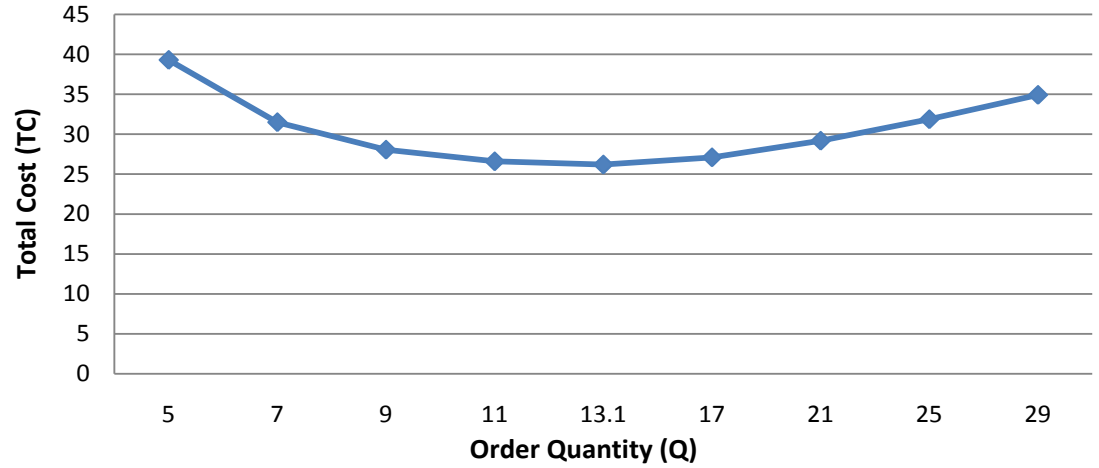

Figure 2. Order quantity verses total cost. 
order quantity $Q^{*}$, optimum length of ordering cycle $T_{1}^{*}$, time cycle $t_{1}^{*}$ at highest inventory and the total optimum inventory cost $T C^{*}$ per unit time in the model affect the inventory system, will be shown in the following table. The sensitivity test is done by changing each of the parameters by $+50 \%,+25 \%$, $+10 \%,-10 \%,-25 \%$ and $-50 \%$ taking one parameter at a time while keeping other parameters unchanged. To do so the scientific calculator has been used all through.

Table 2 shows that small amount of a particular parameter may affect on the values of $t_{1}^{*}, T_{1}^{*}, Q^{*}$ and $T C^{*}$ even at a great extent. On the basis of the results obtained in Table 2, the following observations can be highlighted:

Table 2. Effects of the changes of parameters.

\begin{tabular}{|c|c|c|c|c|c|}
\hline \multirow{2}{*}{ Parameters } & \multirow{2}{*}{ Change in \% } & \multicolumn{4}{|c|}{ Value of } \\
\hline & & $t_{1}^{*}$ & $T_{1}^{*}$ & $Q^{*}$ & $T C^{*}$ \\
\hline \multirow{6}{*}{$K$} & +50 & 1.09 & 7.14 & 20.98 & 32.61 \\
\hline & +25 & 1.09 & 6.52 & 19.15 & 29.36 \\
\hline & +10 & 1.09 & 6.11 & 17.97 & 27.4 \\
\hline & -10 & 1.09 & 5.53 & 16.25 & 24.80 \\
\hline & -25 & 1.09 & 5.05 & 14.84 & 22.85 \\
\hline & -50 & 1.09 & 4.12 & 12.11 & 19.60 \\
\hline \multirow{6}{*}{$\lambda$} & +50 & 0.67 & 6.68 & 13.45 & 26.96 \\
\hline & +25 & 0.83 & 6.07 & 13.32 & 26.66 \\
\hline & +10 & 0.97 & 5.67 & 13.20 & 26.41 \\
\hline & -10 & 1.25 & 5.09 & 12.95 & 26.20 \\
\hline & -25 & 1.59 & 4.61 & 12.68 & 25.98 \\
\hline & -50 & 2.91 & 3.67 & 11.77 & 25.83 \\
\hline \multirow{6}{*}{$d$} & +50 & 1.14 & 7.66 & 13.05 & 26.12 \\
\hline & +25 & 1.11 & 7.65 & 13.07 & 26.16 \\
\hline & +10 & 1.10 & 7.64 & 13.09 & 26.18 \\
\hline & -10 & 1.08 & 7.63 & 13.10 & 26.21 \\
\hline & -25 & 1.07 & 7.62 & 13.12 & 26.26 \\
\hline & -50 & 1.05 & 7.61 & 13.13 & 26.31 \\
\hline \multirow{6}{*}{$a$} & +50 & 1.19 & 7.98 & 15.34 & 31.26 \\
\hline & +25 & 1.14 & 7.80 & 14.32 & 28.92 \\
\hline & +10 & 1.11 & 7.70 & 13.60 & 27.34 \\
\hline & -10 & 1.07 & 7.58 & 12.52 & 25.12 \\
\hline & -25 & 1.04 & 7.46 & 11.56 & 23.42 \\
\hline & -50 & 1.00 & 7.34 & 9.63 & 20.26 \\
\hline \multirow{3}{*}{$h$} & +50 & 1.09 & 6.25 & 10.69 & 32.65 \\
\hline & +25 & 1.09 & 6.84 & 11.71 & 29.34 \\
\hline & +10 & 1.09 & 7.29 & 12.49 & 27.41 \\
\hline
\end{tabular}




\section{Continued}

\begin{tabular}{cccccc}
\hline-10 & 1.09 & 8.06 & 13.80 & 24.79 \\
-25 & 1.09 & 8.83 & 15.13 & 22.83 \\
-50 & 1.09 & 10.82 & 18.52 & 19.55 \\
+50 & 1.09 & 7.6465 & 13.0946 & 26.1018 \\
& +25 & 1.09 & 7.6362 & 13.0947 & 26.1016 \\
& +10 & 1.09 & 7.6363 & 13.0948 & 26.1014 \\
& -10 & 1.09 & 7.6261 & 13.0949 & 26.1009 \\
& -25 & 1.09 & 7.6253 & 13.0951 & 26.1006 \\
& -50 & 1.09 & 7.6150 & 13.0952 & 26.1001 \\
& +50 & 1.09 & 7.6362 & 13.0946 & 26.1021 \\
& +25 & 1.09 & 7.6363 & 13.0947 & 26.1017 \\
& +10 & 1.09 & 7.6364 & 13.0948 & 26.1015 \\
& -10 & 1.09 & 7.6364 & 13.0949 & 26.1013 \\
& -25 & 1.09 & 7.6365 & 13.0951 & 26.1010 \\
& -50 & 1.09 & 7.6366 & 13.0952 & 26.1007 \\
\hline
\end{tabular}

- $t_{1}^{*}$ remains unchanged, while $T_{1}^{*}, Q_{1}^{*}$ and $T C^{*}$ decrease with the increase in the value of the parameter $K$. Here $K$ is moderately sensitive to $T_{1}^{*}, Q_{1}^{*}$ and $T C^{*}$.

- $t_{1}^{*}, T_{1}^{*}, Q_{1}^{*}$ and $T C^{*}$ all the values decrease with the increase in the value of the parameter $\lambda$. Here $\lambda$ is moderately sensitive to $t_{1}^{*}, T_{1}^{*}$ and highly sensitive to $Q_{1}^{*}$ and $T C^{*}$.

- $t_{1}^{*}$ and $T_{1}^{*}$ decrease and $Q_{1}^{*}$ and $T C^{*}$ increase with the increase in the value of the parameter $d$. Here $d$ is moderately sensitive to $t_{1}^{*}, T_{1}^{*}$ and highly sensitive to $Q_{1}^{*}$ and $T C^{*}$.

- $t_{1}^{*}, T_{1}^{*}, Q_{1}^{*}$ and $T C^{*}$ all the values decrease with the increase in the value of the parameter $a$. Here $a$ is moderately sensitive to $t_{1}^{*}, T_{1}^{*}$ and $Q_{1}^{*}$ and highly sensitive to $T C^{*}$.

- $t_{1}^{*}$ remains unchanged, while $T_{1}^{*}$ and $Q_{1}^{*}$ increase and $T C^{*}$ decreases with the increase in the value of the parameter $h$. Here $h$ is moderately sensitive to $T_{1}^{*}$, and highly sensitive to $Q_{1}^{*}$ and $T C^{*}$.

- $t_{1}^{*}$ remains unchanged, while $T_{1}^{*}, Q_{1}^{*}$ and $T C^{*}$ decrease with the increase in the value of the parameter $\mu$. Here $\mu$ is highly sensitive to $T_{1}^{*}, Q_{1}^{*}$ and $T C^{*}$.

\section{Conclusion}

Nowadays, the business firm cannot think its cost minimization without the proper use of the inventory models. By the proper use, management and developing the suitable inventory models, the business enterprise can save its huge amount of inventory cost. In this case, they need to know the actual pattern of 
demand in the market. This demand is not always fixed it always fluctuates. A suitable model is developed considering the actual market demand. The inventory model we have proposed in this paper is dependent on the stock allowing the defective items in the production cycle. The model also considers the deterioration, so due to the finite life of the items this model gives the correct result. In the proposed model, the production rate and the decay have been considered constant all through. The model develops an algorithm to determine the optimum ordering cost, total optimum inventory cost, optimum time at maximum inventory level and optimum time cycle. The model could establish order level $Q^{*}=13.10$, the total optimum inventory cost $T C^{*}=26.19$ units.

\section{Conflicts of Interest}

The authors declare no conflicts of interest regarding the publication of this paper.

\section{References}

[1] Harris, F.W. (1915) Operations and Costs. A. W. Shaw Company, Chicago, 48-54.

[2] Whitin, T.M. (1957) Theory of Inventory Management. Princeton University Press, Princeton, 62-72.

[3] Ghare, P.M. and Schrader, G.F. (1963) A Model for an Exponential Decaying Inventory. Journal of Industrial Engineering, 14, 238-243.

[4] Hou, K.-L. (2006) An Inventory Model for Deteriorating Items with Stock Dependent Consumption Rate and Shortages under Inflation and Time Discounting. European Journal of Operational Research, 168, 463-474. https://doi.org/10.1016/j.ejor.2004.05.011

[5] Chund, C.-J. and Wee, H.-M. (2008) Scheduling and Replenishment Plan for an Integrated Deteriorating Inventory Model with Stock-Dependent Selling Rate. International Journal of Advanced Manufacturing Technology, 35, 665-679. https://doi.org/10.1007/s00170-006-0744-7

[6] Heng, J.K., Labbani, J. and Linn, R.J. (1991) An Order Level Lot Size Inventory Model for Deteriorating Items with Finite Replenishment Rate. Computer and Industrial Engineering, 20, 187-197. https://doi.org/10.1016/0360-8352(91)90024-Z

[7] Skouri, K. and Papachristos, S. (2002) A Continuous Review Inventory Model, with Deteriorating Items, Time-Varying Demand, Linear Replenishment Cost, Partially Time-Varying Backlogging. Applied Mathematical Modeling, 26, 603-617. https://doi.org/10.1016/S0307-904X(01)00071-3

[8] Cheng, M.B. and Wang, G.Q. (2009) A Note on the Inventory Model for Deteriorating Items with Trapezoidal Type Demand Rate. Computers and Industrial Engineering, 56, 1296-1300. https://doi.org/10.1016/j.cie.2008.07.020

[9] Sarker, B.R., Mukhaerjee, S. and Balam, C.V. (1997) An Order-Level Lot Size Inventory Model with Inventory-Level Dependent Demand and Deterioration. International Journal of Production Economics, 48, 227-236. https://doi.org/10.1016/S0925-5273(96)00107-7

[10] Sana, S.S. and Chaudhuri, K.S. (2008) A Deterministic EOQ Model with Delay in Payments and Price-Discount Offers. European Journal of Operational Research, 184, 509-533. https://doi.org/10.1016/j.ejor.2006.11.023 
[11] Shah, Y.K. and Jaiswal, M.C. (1977) Order Level Inventory Model for a System of Constant Rate of Deterioration. Opsearch, 14, 174-184.

[12] Dye, C.-Y. (2007) Joint Pricing and Ordering Policy for a Deteriorating Inventory with Partial Backlogging. Omega, 35, 184-189. https://doi.org/10.1016/j.omega.2005.05.002

[13] Shavandi, H. and Sozorgi, B. (2012) Developing a Location-Inventory Model under Fuzzy Environment. International Journal of Advanced Manufacturing Technology, 63, 191-200. https://doi.org/10.1007/s00170-012-3897-6

[14] Mishra, V.K., Singh, L.S. and Kumar, R. (2013) An Inventory Model for Deteriorating Items with Time Dependent Demand and Time Varying Holding Cost under Partial Backlogging. Journal of Industrial Engineering International, 9, Article No. 4. https://doi.org/10.1186/2251-712X-9-4

[15] Ekramol Islam, M. (2004) A Production Inventory Model for Deteriorating Items with Various Production Rates and Constant Demand. In: Proceedings of the Annual Conference of KMA and National Seminar on Fuzzy Mathematics and Applications, Payyanur College, Payyanur, No. 2, January 2015, 14-23.

[16] Ekramol Islam, M. (2015) A Production Inventory with Three Production Rates and Constant Demands. Bangladesh Islamic University Journal, 1, 14-20.

[17] Ukil, S.I., Ahmed, M.M., Sultana, S. and Uddin, Md.S. (2015) Effect on Probabilistic Continuous EOQ Review Model after Applying Third Party Logistics. Journal of Mechanics of Continua and Mathematical Science, 9, 1385-1396.

[18] Sivazlin, B.D. and Stenfel, L.E. (1975) Analysis of System in Operations Research. 203-230.

[19] Pakkala, T.P.M. and Achary, K.K. (1992) A Deterministic Inventory Model for Deteriorating Items with Two Warehouses and Finite Replenishment Rate. European Journal of Operational Research, 57, 71-76. https://doi.org/10.1016/0377-2217(92)90306-T

[20] Billington, P.L. (1987) The Classic Economic Production Quantity Model with Set up Cost as a Function of Capital Expenditure. Decision Series, 18, 25-42. https://doi.org/10.1111/j.1540-5915.1987.tb01501.x

[21] Abad, P.L. (1996) Optimal Pricing and Lot-Sizing under Conditions of Perishability and Partial Backordering. Management Science, 42, 1093-1104.

https://doi.org/10.1287/mnsc.42.8.1093

[22] Singh, T. and Pattnayak, H. (2013) An EOQ Model for Deteriorating Items with Linear Demand, Variable Deterioration and Partial Backlogging. Journal of Service Science and Management, 6, 186-190. https://doi.org/10.4236/jssm.2013.62019

[23] Singh, T. and Pattnayak, H. (2012) An EOQ Model for a Deteriorating Item with Time Dependent Exponentially Declining Demand under Permissible Delay in Payment. IOSR Journal of Mathematics, 2, 30-37. https://doi.org/10.9790/5728-0223037

[24] Singh, T. and Pattnayak, H. (2013) An EOQ Model for a Deteriorating Item with Time Dependent Quadratic Demand and Variable Deterioration under Permissible Delay in Payment. Applied Mathematical Science, 7, 2939-2951. https://doi.org/10.12988/ams.2013.13261

[25] Giri, B.C., Goswami, A. and Chaudhuri, K.S. (1996) An EOQ Model for Deteriorating Items with Time Varying Demand and Cost. Journal of Operational Research Society, 47, 1398-1405. https://doi.org/10.1057/jors.1996.175

[26] Amutha, R. and Chandrasekaran, E. (2013) An EOQ Model for Deteriorating Items 
with Quadratic Demand and Tie Dependent Holding Cost. International Journal of Emerging Science and Engineering, 1, 5-6.

[27] Ouyang, L.-Y., Wu, K.-S. and Cheng, M.-C. (2005) An Inventory Model for Deteriorating Items with Exponential Declining Demand and Partial Backlogging. Yugoslav Journal of Operation Research, 15, 277-288.

https://doi.org/10.2298/YJOR0502277O

[28] Dave, U. and Patel, L.K. (2017) ( $T, S_{i}$ ) Policy Inventory Model for Deteriorating Items with Time Proportional Demand. Journal of the Operational Research Society, 32, 137-142. https://doi.org/10.1057/jors.1981.27

[29] Teng, J.-T., Chern, M.-S., Yang, H.-L. and Wang, Y.J. (1999) Deterministic Lot Size Inventory Models with Shortages and Deteriorating for Fluctuating Demand. Operation Research Letters, 24, 65-72. https://doi.org/10.1016/S0167-6377(98)00042-X 